information recentlv received from Japan, 337 earthquakes occurred in the south of the country on January 12 , the strongest of all being recorded at Nagasaki at 6h. 29m. 27s. The coincidence is so close as to justify Prof. Belar's conclusion that the earthquake recorded at Laibach originated near the south coast of Japan. That the earthquake was of considerable strength is evident from an account by the Rev. A. C. Hutchinson, of Kagoshima, which appeared in The Times for February 6. "The earth," he says, "seemed to leap convulsively upwards. The quaking was so great for two minutes that it was difficult to stand."

Prof. Belar remarks that the interest of the seismogram is due to the possible connection of the earthquake with the eruption of Sakurajami on the same day. As a rule, the foci of volcanic earthquakes are close to the surface, and the vibrations are insensible, even with instrumental aid, at considerable distances from the epicentre. If the shock recorded at Laibach were of volcanic fifty miles or more) from the recently active volcano of Sakurajami, for the seismic sea-waves which swept over the low-lying parts of Kagoshima arrived half-an-hour or more after the earthquake was felt in that city. But, notwithstanding this, it seems probable that Prof. Belar is correct in assigning to the earthquake a place among the volcanic phenomena, and to its focus a depth considerably greater than is usual in volcanic earthquakes.

C. Davison.

\section{ALBINISM. ${ }^{1}$}

THE word albinism is used in several senses. In the strictest sense it is used only of cases in which pigment is completely, or apparently completely, absent from the skin, hair, and eyes; in the widest sense it includes many grades of deficiency of pigment, whether generally over the body or in restricted areas. The memoir before us illustrates the difficulty of defining albinism, for according to the authors all grades of pigment

$$
\text { 10 } 42^{\mathrm{m}}
$$
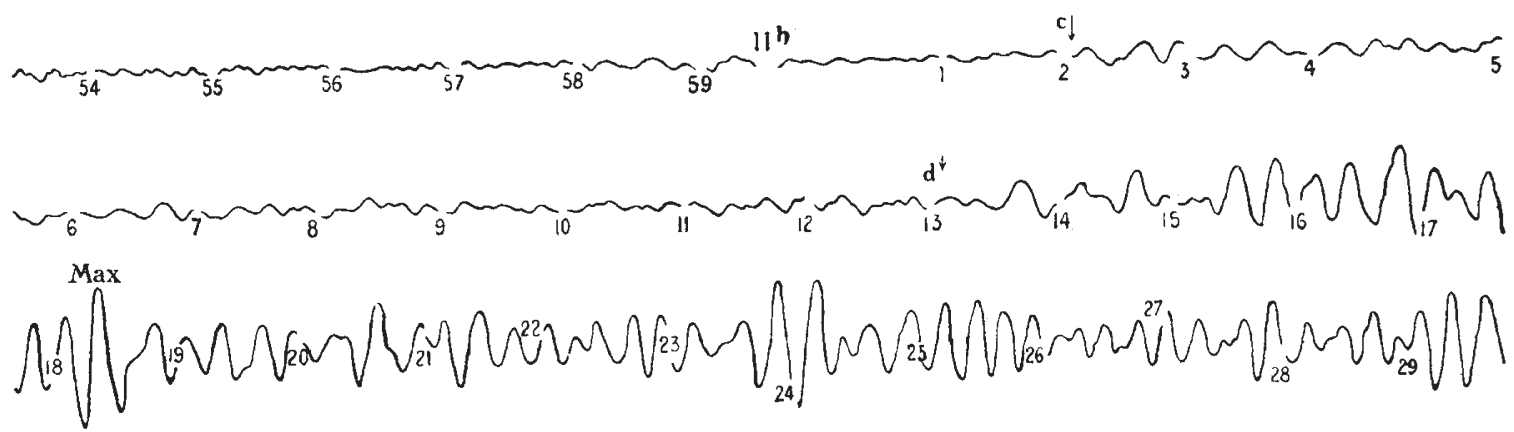

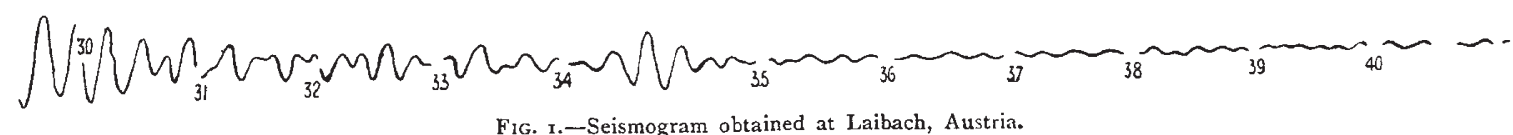

origin, this would be the first instance of a volcanic earthquake being recorded across an entire continent since the horizontal pendulum was adapted for seismographic purposes.

Of earthquakes connected with a volcanic eruption, those which are due to the actual explosions are usually of less intensity than those which occur at other times, while the strongest shocks may originate at some distance from the volcano. For instance, in the south-west corner of Hokkaido (the northern island of Japan), there is a group of volcanoes, of which three-the Komaga-take, the Tarumai-san, and the Usu-san-have been active recently. Earthquakes are extremely rare in this part of the country, but each of the last four eruptions has taken place in fairly close connection with a strong earthquake the epicentre of which has been from sixty to 170 miles from the volcano. ${ }^{1}$

It seems clear that the earthquake of January I2 must have originated at some distance (perhaps

1 F. Omori, Bull. Imp. Earthq. Inves. Com., vol. v., хөгт, pp. 5-7. NO. 23I3, VOL. 92] reduction occur, both in Man and other Vertebrates, so that no sharp line would seem to exist between total and partial albinism. There is little doubt, however, that a number of quite different causes may give rise to pigment reduction, and that much might be done to classify the various manifestations into natural groups. Some of the more outlying types are already clearly separable, e.g. pathological leucoderma, and the whitening of the hair of certain species in winter, which is due to a shedding of pigmented hair and its replacement by white in autumn, followed by moult in the other direction in the spring.

Another group of so-called albinotic cases can be separated by their mode of inheritance. An inspection of pedigrees at once reveals the fact that some cases of "partial albinism" in man, in which the skin is spotted with white, or in which there is a white patch of hair on a body 1 "A Monograph on Aluinism in Man." By Karl Pearson, F.R.S., E. Nettleship, F.R.S., and C. H. Usher. Part ii., Text. Pp. 265-524 tatlas. Price, $30 s$. net. Part iv., Text. Pp. iv. $+136+x x i i i+a t l a s$ (London: Dulau \& Co., Ltd., rgr3.) Price, 2rs. net. (Drapers' Company Research Memoirs. Biometric Series, viii. and ix.) 
otherwise normally coloured, are inherited as typical Mendelian dominants, the affection being always transmitted in the direct line. On the other hand, many, probably the majority, of cases of complete or nearly complete albinism behave as recessives, and appear especially in the offspring of consanguineous marriages between affected stocks.

When the more sharply defined cases have been separated out, there remains a large mass of material which still requires analysis, and one of the most hopeful ways of dealing with this seems to be by a comparison with cases in animals which have been or might be worked out experimentally. Such experiment has already shown, first, that skin and coat colour is due to the combined effect of at least two separately inherited factors, one of which is necessary for the production of any kind of pigment, while the other determines the colour of the pigment which is produced. Vertebrate albinos are commonly produced by the absence of the first factor, and may therefore bear the factors which determine particular colours, although they do not show them. Albinos are therefore not all alike in their inherited constitution, and it is probably only by disentangling the various factors involved that a complete understanding of the causes of human albinism will be obtained. Secondly, experiment with animals shows that piebalding is completely distinct from total albinism in its inheritance, and that if a piebald appears when an albino is crossed with a self-colour, this is not due to mosaic inheritance, but to the fact that the albino bears the factor for piebalding-is, in fact, a piebald from which the pigment factor is lacking. Thirdly, there is evidence that some cases of lack of pigment are due to an inhibiting factor which interferes with the development of pigment, even in the presence of both the required colour-factors. When complications of this kind have been shown to exist in animals which can be subjected to rigorously controlled experiment, it is not surprising that the examination of human albinos and their pedigrees reveals irregularities.

A comparison with animal cases suggests, however, that by the careful collection of evidence, and especially by the classification of cases (I) according to the results of clinical observation, supplemented by microscopical examination when possible, and (2) according to the mode of inheritance, much could be done to disentangle the various factors which are involved. Much of the preliminary work in this direction could be done with the data now available, but as long as we continue to group together, in thought as well as in name, such different phenomena as total absence of pigment, general reduction of pigment, piebalding, and wall-eye, and, from the point of view of inheritance, cases which are clear Mendelian dominants, others which are scarcely less clearly recessive, and others, again, which have undoubted sex-limited inheritance, so long the present confusion will continue.

The monograph before us, though scarcely making any attempt at a classification such as we suggest, will provide most useful material for future workers on the subject. It gives a full account of the clinical and microscopic characters of various kinds of albinism in the widest sense of the word, both in man and animals; discusses their occurrence and geographical distribution, and includes, in part iv., nearly 7oo fully described pedigrees, some of them extending to roo or more individuals.

\section{PROF. S. P. LANGLEY AND AVIATION.}

I have brought to a close the portion of the work which seemed to be specially mine, the demonstration of the practicability of mechanical flight; and for the next stage, which is the commercial and practical development of the idea, it is probable that the world may look to others. The world, indeed, will be supine if it do not realise that a new possibility has come to it, and that the great universal highway overhead is now soon to be opened.

THUS spoke the late secretary of the Smithsonian Institution, Samuel Pierpont Langley, after his memorable experiment of May 6, 1896, in which he launched a heavier-than-air machine in the air, which flew under its own power (steam), traversing a distance of half a mile. This experiment it was that convinced the world of the practicability of mechanical flight, and which crowned the success of all his previous experimental researches. It was not until the year 1903 (December I7) that the Brothers Wright, Wilbur and Orville, fitted a motor to their gliding machine, and made two flights, the first successful flights ever made by man in a heavier-than-air machine driven by its own power.

It was a fitting tribute of the Board of Regents of the Smithsonian Institution to found, on December I5, I908, a Langley medal "to be awarded for specially meritorious investigations in connection with the science of aerodromics and its application to aviation," and it was most appropriate that the brothers Wilbur and Orville Wright were the first (I909) to receive the award. The presentation of this medal is now made on May 6, a date selected in order that the ceremonies incident to the presentation may take place in connection with the observance of "Langley Day," which was established by the Aero Club of Washington in I9I I to commemorate Langley's achievement.

A recent Smithsonian Institution publication (No. 2233) contains an account of the exercises on the occasion of the presentation of the Langley Medal and the unveiling of the Langley Memorial Tablet on May 6, I9I3, including the addresses of Dr. Alexander Graham Bell, Monsieur J. J. Jusserand, the Ambassador to the United States, Dr. John A. Brashear, and the secretary, Dr. Charles D. Walcott. The bronze memorial tablet is situated in the Smithsonian building, and represents Prof. Langley seated on a terrace where he has a clear view of the heavens, and, in a meditative mood, is observing the flight of birds, while in his mind he sees his aerodrome soaring above them.

NO. 23 I3, VOL. 92] 